\title{
Finding Common Ground: A Synthesis of Science and Mathematics Teacher Educators' Experiences with Professional Growth
}

\author{
Meredith Park Rogers ${ }^{1} \cdot$ Amanda Berry $^{2} \cdot$ Konrad Krainer $^{3} \cdot$ Ruhama Even $^{4}$
}

Received: 30 April 2021 / Accepted: 30 April 2021 / Published online: 3 July 2021

(C) The Author(s) 2021

\begin{abstract}
The seven articles that comprise this Special Issue examine the professional growth of mathematics and science teacher educators across different contexts and different foci of who is the teacher educator being studied. Despite these differences, a common thread running throughout these seven articles is the need for learning to be situated in collaboration with others. In this final article, we examine the contribution of these articles through two perspectives: that of the collaborative contexts supporting the professional growth of mathematics and science teacher educators, and the role of disciplinary knowledge as part of the purpose for teacher educators' professional growth. We notice that collaboration can take on very different structures in supporting teacher educators' professional learning due to the different purposes and roles of the teacher educators in the studies. We also notice that while collaboration figures as an important component in all of the studies, the disciplinary specific aspects of collaboration, i.e., how collaboration might be negotiated differently by teacher educators in mathematics and science, is still not well understood. Overall, these articles provide important insights that help to shed new light on the complex and multifaceted nature
\end{abstract}

Meredith Park Rogers

mparkrog@indiana.edu

$\triangle$ Konrad Krainer

konrad.krainer@aau.at

Amanda Berry

amanda.berry@monash.edu

Ruhama Even

ruhama.even@weizmann.ac.il

1 Indiana University - Bloomington, Bloomington, IN, USA

2 Monash University, Clayton, Australia

3 University of Klagenfurt, Klagenfurt, Austria

4 Weizmann Institute of Science, Rehovot, Israel 
of teacher educators' learning and growth and provide productive avenues for future research.

Keywords Collaboration $\cdot$ Teacher educator $\cdot$ Professional growth $\cdot$ Professional knowledge

Ping et al. (2018) recently published a systematic review of teacher educator professional learning; however, missing from this review is any connection to understanding disciplinary specific teacher educator learning. The intent of this special issue of the International Journal of Science and Mathematics Education is to bring to light how researchers are working within and across the science and mathematics education communities to enhance teacher education by discussing important aspects regarding the professional growth of mathematics and science teacher educators. Thus, putting a spotlight specifically on the kinds of frameworks for professional growth guiding our ideas about how to study teacher educators' learning and development, what models or programmatic experiences appear to be working well, and what common practices are occurring in the fields of mathematics and science education.

The seven articles selected for this issue provide a range of ideas related to these questions and offer recommendations for others in the field to consider when working in the context of mathematics and science teacher education. More specifically, we noticed across these articles how authors have taken up different ideas as to who is a teacher educator. For example, we see in four of the papers the authors themselves are the focus of study and are seeking to understand their professional identity (see Lloyd et al., 2021; Weinberg et al., 2021) or are discussing models of professional growth established at their institution and their own learning as participants in the program (see Hanuscin et al., 2021 and Triantafillou et al., 2021). Other authors are a step or two removed as the teacher educator of focus, and as such are not examining their own learning as teacher educators, rather how a graduate student (see Superfine \& Pitvorec, 2021), district level subject advisors (see Venkat \& Askew, 2021), or school level teacher leaders (see Borko et al., 2021) are growing professionally as educators of teachers. Due to these differences in who is being positioned as the teacher educator participant(s) for the study, the methodological framework also varies from self-study, to case study, to narrative inquiry, to programmatic reviews. Therefore, considering the range of perspectives of who constitutes a teacher educator, and the variation in methodologies employed by the researchers, we decided to focus our attention on what we identified as the collaborative context supporting the professional growth and the role of disciplinary knowledge as a component of professional growth.

To begin, we mention in our introductory paper (Krainer et al., 2021) that the seven articles in this issue discuss professional growth in different contexts and different foci of who is the teacher educator being studied. Despite these differences, however, one aspect of teacher educator professional growth we found constant across these seven studies is the need for learning to be situated in collaboration with others. This stance follows a socio-cultural perspective to learning (Anderson, 2007; National Research Council, 2005) found in much of the literature on mathematics and science classroom learning. Ping et al. (2018) also identify collaboration as a common professional learning activity from their review of 123 articles on teacher educators' professional 
learning across disciplines. This led us to our second theme of how disciplinary knowledge (i.e. subject matter knowledge) is included as part of the purpose for professional growth described in these seven studies. These two themes, role of collaboration and inclusion of subject matter knowledge, frame this epilogue.

\section{Theme 1: Role of Collaboration}

The notion of collaboration, or collaborative learning, as an educational strategy for supporting teaching and learning is well-established in social sciences research literature (Borko \& Potari, 2020; Laal \& Ghodsi, 2012; van der Linden et al., 2000). In particular, as a pedagogical approach, it fits well within contemporary views of sociocultural or socio-constructivist learning as described by Vygotsky (Newman \& Latifi, 2021). For studies that situate themselves methodologically as following a self-study approach, it is understandable that collaboration would be central to the work described in the study, as it is frequently employed by self-study researchers as a means of establishing trustworthiness and to provide critical insight into the practice of studying teacher education (Mena \& Russell, 2017). Additionally, well-established frameworks of professional learning, such as a Community of Practice (CoP; Lave \& Wenger, 1991; Wenger, 1998), also rest on the premise that for learning to occur there needs to be member interaction through sharing of experiences and collective meaning making. Examining the reference to collaboration in the context of teaching and learning across the seven studies, we identified three ways we saw the notion of collaboration being discussed. We refer to the three forms of collaboration presented in these seven studies on mathematics and science teacher professional growth as being either informally, semi-formally, or formally structured.

\section{Collaboration in an Informal Structure Supporting Teacher Educator Professional Growth}

An informal learning structure is exemplified in the two studies by Weinberg and colleagues and Lloyd and colleagues. In both of these studies, the professional growth of the teacher educator being studied is that of the authors themselves. Their research aligns with many of the reasons Ping et al. (2018) found across the literature were examples of content and reasons why teacher educators study their own professional learning. With respect to Weinberg and colleagues and Lloyd and colleagues, the role of collaboration was a natural element of their work. Their studies were self-initiated because of curiosity and personal interest in understanding their own professional identity as a teacher educator, as well as a desire to support their colleagues in doing the same. Participation in the collaborative learning experience described in these two studies was voluntary and participants felt a sense of equal partnership. In both studies, reference is also made specifically to the notion of an established $\mathrm{CoP}$ and as such collaboration was a required component of the partnership. Additionally, both of these studies describe a mutually beneficial collaboration that grew out of long-standing relationships with all members of the community. Table 1 summarizes the role of collaboration within the informal structure of a CoP employed in these two studies. 
Table 1 Role of collaboration within informally structured models supporting teacher educator professional growth

Authors Guiding framework and focus of collaboration Key aspects of collaboration in teacher educator professional growth

\begin{tabular}{|c|c|c|}
\hline $\begin{array}{c}\text { Weinberg } \\
\text { et al. } \\
\text { (2021) }\end{array}$ & $\begin{array}{l}\text { - Figured worlds used to frame identity } \\
\text { formation } \\
\text { - Figured worlds are informed by socio-cultural } \\
\text { theories } \\
\text { - Focus on CoP interaction, serving as a type of } \\
\text { figured world because of the nature of } \\
\text { member interaction }\end{array}$ & $\begin{array}{l}\text { - Long-standing personal and professional re- } \\
\text { lationships } \\
\text { - The collaboration of the CoP positioned } \\
\text { learning as a social activity, with key features } \\
\text { of trust, advocacy, mutual understanding, } \\
\text { flexibility, and distributed leadership } \\
\text { - Despite mutual participation, meaning making } \\
\text { and shared resources, individuals also have } \\
\text { agency over their own identity development }\end{array}$ \\
\hline $\begin{array}{l}\text { Lloyd } \\
\qquad \text { et al. } \\
\qquad(2021)\end{array}$ & $\begin{array}{l}\text { - Perspective on teacher educator identity } \\
\text { informed by "situated learning," thus } \\
\text { socially constructed and negotiated within a } \\
\text { CoP } \\
\text { - Focus on duoethnography as a means of } \\
\text { relaying shared stories }\end{array}$ & $\begin{array}{l}\text { - Long-standing partnership between university } \\
\text { and local school district with Professional } \\
\text { Development School model. Within this } \\
\text { model, university and elementary school } \\
\text { work together to teach methods courses and } \\
\text { connect field experience authentically to the } \\
\text { classroom for preservice teachers } \\
\text { - Features of collaboration included intentional } \\
\text { reflective discussion with colleagues of } \\
\text { diverse professional expertise, thus } \\
\text { demonstrating vulnerability as one opens up } \\
\text { perspectives and practices of self to others }\end{array}$ \\
\hline
\end{tabular}

For the five remaining studies, however, collaboration did not necessarily play a personal role, so much as a structural role for other goals to be accomplished. This resulted in the collaborative relationships not being as clearly defined as in the Weinberg and colleagues' and Lloyd and colleagues' papers. However, differences were noted even in the remaining five papers and for this reason we divided them into two additional groups - semi-formal and formal collaborative structures.

\section{Collaboration in a Semi-Formal Structure Supporting Teacher Educator Professional Growth}

Hanuscin et al. (2021), Superfine and Pitvorec (2021), and Triantafillou et al. (2021) were identified as falling under the semi-formal structure with respect to how collaboration was being employed. In each of these studies, there was an established institutional framework in place that guided how the community members interacted and collaborated in studying and reflecting on their practice. Unlike the two informal structured collaborations, the collaborations in the semi-formal structure category did not emerge from a long-standing partnership between members, and in fact new members came and went from the collaborative community depending on the needs of the individual. There was some flexibility with what an individual might contribute to the collaboration, but also what they gain from participating in the community. It is notable in all three studies identified as semi-formal structure collaborations that members seemed to view their participation as a part of the institutional expectation, 
or what Ping et al. (2018) categorize as an "external requirement" for why teacher educators sometimes engage in opportunities for professional growth. Despite the collaborative structure existing because of an institutional expectation, none of the participants in the studies suggested they felt pressured to be involved in the collaboration, rather they embraced the support their institutions were providing in establishing these opportunities for professional growth with colleagues within or across mathematics, science, and STEM disciplines. Therefore, we posit the variation we see in the outcomes of the three semi-formal structured collaboration studies has to do with the reasons for the collaboration occurring in the first place. These differences are highlighted in Table 2.

Table 2 Role of collaboration within semi-structured models supporting teacher educator professional growth

\begin{tabular}{lll}
\hline Authors & $\begin{array}{l}\text { Guiding framework and } \\
\text { focus of collaboration }\end{array}$ & $\begin{array}{l}\text { Key aspects of collaboration in teacher } \\
\text { educator professional growth }\end{array}$
\end{tabular}

\begin{tabular}{cc}
\hline Hanuscin et al. & " \\
(2021) & 2009), referring to a collaboratively \\
& structured learning experience for \\
& faculty, but distinct from co-teaching, \\
& paired teaching, or mentoring approaches \\
- & Neither CoP nor inquiry mentioned, but \\
& collaboration is critical among pairs \\
& shadowing each other
\end{tabular}

- A cross-disciplinary model featuring both modeling and critical reflection on pedagogical decision-making

- Each shadowing experience is negotiated and unique, with 5 features of professional growth identified across the shadow pairings: (1) focus on learning versus evaluation, (2) personalized and reciprocal, (3) emergent nature of learning goals, (4) flexible structure, and (5) long-term

$\begin{array}{ll}\begin{array}{c}\text { Superfine and } \\ \text { Pitvorec }\end{array} & \text { Focus on identifying "problems of } \\ (2021) & \text { practice" as lens for analysis and growth } \\ \text { in the CoP } \\ \text { - CoP-specifically the apprenticeship ap- } \\ \text { proach (Lave \& Wenger, 1991; Wenger, } \\ \text { 1998) }\end{array}$

- Agreement on the use of Mathematics Teacher Educator Lesson Plans as artifacts for reifying the community's knowledge building

- CoP features-members shared goals, practices, and history

- A model of $\mathrm{CoP}$ with varied levels of expertise, thus situating learning as apprenticeship with novice Mathematics Teacher Educators learning from more experienced members

Triantafillou et al. - Focus of study was supporting (2021)

mathematics and science teachers with learning to collaborate in a Community of Inquiry for integrated STEM learning that seeks to develop curriculum aligning similar epistemological practices of STEM

- Community of Inquiry employed, along with Activity Theory, as a theoretical and analytical tool for studying the complexity of teacher education and the role of teacher educators in supporting mathematics and science teachers to collaborate
- Teacher educators identified the complexities of cross-disciplinary teacher education and collaboration; the need for addressing diversity among disciplines, curricular differences, teacher subject matter and program priorities

- Through collaborative discussions with teachers and across the PD team, teacher educators recognized their own research backgrounds may be limiting their understanding of the epistemological stances of multiple disciplines 
It is important to note that, within this semi-formal category, Superfine and Pitvorec were not identified as participants of their study, as the authors of the other two papers were. This suggests that a semi-formal approach to collaboration as a structure for professional growth can allow for flexibility in who is being studied, what is being studied, and why, thus opening up opportunities for various perspectives on teacher educator professional learning, such as expert/novice or mentor/mentee types of relationships, to be examined. With respect to these sorts of relationships, however, there is the possibility of power dynamics to exist within the collaborative structure (Cuenca \& Park Rogers, 2019). When power differences can naturally occur in the collaboration, even if the focus is on improving a tool for instruction, such as the lesson plan in the Superfine and Pitvorec (2021) study, or modeling how to engage with others that may not have the same disciplinary background (see both Hanuscin et al., 2021 and Triantafillou et al., 2021), the one in the more knowledgeable position at the time has power over the one observing to learn. This can unintentionally lead the one in the mentee or apprentice position feeling emotions of inadequacy. We commend Hanuscin et al. (2021) raising "emotional development" as a dimension of teacher educator professional growth that needs to be addressed and carefully negotiated in semiformal collaborative structures where both expert and novice teacher educators are learning with and from each other.

\section{Collaboration in a Formal Structure Supporting Teacher Educator Professional Growth}

The final category of collaboration identified across these articles we referred to as formal. The Venkat and Askew (2021) paper, as well as Borko et al.'s (2021) study, fits under this category. In both cases, collaboration was never directly referred to as a part of the professional growth process for the teacher educators being studied, rather it was implied or assumed as a component of the larger professional development program that was being investigated in each study. Additionally, the authors of these two papers were not participants in the learning experience but facilitators of the learning with the goal of supporting others (teacher leaders or subject matter advisors) to develop as educators of teachers in their work with classroom teachers. Therefore, there appeared to be a trickle-down effect with collaboration in these two studies as the teacher leaders (in Borko et al., 2021) and subject matter advisors (in Venkat \& Askew, 2021) learned from the authors about a particular mathematics curriculum or program, and the skills for how to work with the classroom teachers to support them with implementing it. Therefore, these two papers suggest that collaboration in a formal structure could receive little direct attention, but still serves as a mechanism for effective delivery of the larger professional development goals. The manner with which collaboration is implied in Borko et al. (2021), and Venkat and Askew (2021) is described in Table 3.

\section{Summary of Theme One}

The notion of collaboration as a mode for learning is not a new concept and is encouraged in most learning contexts. However, we see from the seven articles in this special issue that collaboration can take on very different structures (informal, semiformal, and formal) when it comes to its use in supporting teacher educator professional 
Table 3 Role of collaboration within formal models supporting teacher educator professional growth

Authors Guiding framework and focus of collaboration Key aspects of collaboration in teacher educator professional growth

Venkat and • Heyd-Metzuyanim (2017) "Ring" and

Askew "Overlapping" models of relationships be-

(2021) tween communities in mathematics education

- Focus on understanding the Mathematics Subject Advisor's (MSAs) and classroom teacher's collaboration with respect to delivery of lessons from intervention

Borko

et al.

(2021)
- Guiding the design and of the PD and the analysis of the PD for the study were the models - "Learning to Lead Cycle" (adapted from McDonald, Kazemi, \& Kavanagh, 2013) and Prediger and Pöhler (2019) three-Tetrahedron Model of PD, which illustrates a pathway of interactions of facilitators of PD

- At each level, PD is designed to promote learning that involves lifting (i.e. examples from classroom practice to situate the learning), nesting (i.e. the learning in the goals of the PD), and unpacking (i.e. a reflective strategy relating learning across the PD levels of the model)
- University researchers arranged things to ensure the MSAs would be able to collaborate with a participating classroom teacher on all 4 lessons from the intervention. This "guaranteed" time had not easily been established for MSAs before

- No specific mention though as to how the researchers encouraged/guided the collaboration efforts between MSAs and classroom teachers. The MSAs approached this on their own terms

- Key feature of this model is to build research-practice partnership in order to build PD capacity at the school level with the use of teacher leaders

- The focus was on developing teacher leaders who would then return to schools to collaborate with colleagues with learning to adopt the district adopted curriculum

- No direct mention on how teacher leaders learned to specifically collaborate with teachers in learning about the curriculum, but one may infer collaboration occurring at the reflective stages (unpacking)

growth. These differences may occur because of the purpose of the learning, the structure or guiding framework for the learning (e.g. Community of Practice), the criteria for how collaboration will be established, and who is identified as a teacher educator. Despite learning about the important role of collaboration in the context of each paper, what is still not understood is how collaboration might be negotiated differently by teacher educators in mathematics compared to science. Of the seven articles presented in this issue, only two (Weinberg et al. (2021); Triantafillou et al. (2021)) represent a collaboration between mathematics and science educators. In Weinberg et al. (2021), while "STEM disciplinary expert" was a domain of STEM identity these authors were considering as part of their STEM identity development, it appeared that only one member of the group experienced (limited) transformation in this domain. Thus, understanding the differences in disciplinary perspectives among the teacher educators and how these differences may have impacted their collaboration was given little attention. Triantafillou et al. (2021) positioned interdisciplinary connections between STEM educators as a goal of their work with teachers. However, they found it difficult to follow through on this goal because of the differences in epistemological and ontological views found in the natural and applied science disciplines. They concluded that for science and mathematics collaborations to be successful in modeling interdisciplinary curriculum development, it is important for teacher educators to have 
an accurate understanding of key disciplinary practices and ways of knowing held by the different disciplines; only then can teacher educators model how to accurately portray integrated curricular approaches that complement and support purposeful connections across the disciplines. Considering the results of these two studies (Weinberg et al. (2021) and Triantafillou et al. (2021)) leaves one questioning the role of disciplinary knowledge for teacher educators. To what extent does disciplinary knowledge play a role, or should it play a role, when collaborating with colleagues of similar or different disciplines for the purpose of growing in our understandings of, and practices of, being science and mathematics teacher educators? We explore this latter question in the next section.

\section{Theme 2: The Role of Disciplinary Knowledge}

A second theme we considered from these studies is the role of disciplinary knowledge in teacher educators' professional growth. Given this special issue focuses on mathematics, science, and STEM teacher educators, we wanted to understand how the subject domain figures in these studies, and what role it takes in one's development as a teacher educator. As we mentioned in our opening article (Krainer et al., 2021), Shulman (1986) proposed that teachers possess a unique kind of knowledge that distinguishes them from subject matter specialists which he termed pedagogical content knowledge (PCK). By naming PCK as the integration of subject specific content and pedagogy, Shulman (1986) aimed to address a "missing paradigm" in research on teaching and teacher knowledge that, up until that time, had predominantly focused on generic aspects of teaching.

So, what does this idea of a subject specific pedagogical knowledge mean when viewed from the perspective of a teacher educator? Obviously, teacher educators need to develop a wide range of skills, attitudes, and knowledge, some of which are generic (for example, being able to work in a team or having excellent communication skills), while others are more discipline specific (e.g. knowledge of how to teach particular subject matter in ways that support student learning). It could be argued that teacher educators at least need well-developed PCK for teaching specific school subject matter, as well as knowledge of how to teach teachers about that subject matter knowledge so that they are able to teach it effectively to their students. Abell, Park Rogers, Hanuscin, Lee, and Gagnon (2009) captured this latter idea as "a parallel form of PCK" for teacher educators that includes "knowledge about curriculum, instruction, and assessment for teaching science methods courses and supervising field experiences, as well as ... knowledge about preservice teachers and orientations to teaching science teachers" ( $\mathrm{p}$. 79).

The set of studies that comprise this special issue on teacher educator professional growth illustrate a wide range of ways in which subject matter plays a role in teacher educators' professional growth. In some studies, there is an explicit disciplinary focus (e.g. Hanuscin et al., 2021; Superfine \& Pitvorec, 2021; Venkat \& Askew, 2021), in other studies, the discipline is considered in relationship with other foci (e.g. Lloyd et al., 2021; Triantafillou et al., 2021; Weinberg et al., 2021), and in others, the discipline sits more in the background, as a context for the study (e.g. Borko et al., 2021). We now highlight 
the varied approaches that each of these studies takes to including subject matter as a component of teacher educator professional growth.

The studies of Hanuscin et al. (2021) and Superfine and Pitvorec (2021) both focus on university-based teacher educators' professional growth. In Hanuscin et al.'s (2021) study, teacher educators' professional growth occurs in terms of both conceptual understandings of their subject area, making connections between concepts, as well as improved knowledge of prospective teachers' understanding about particular scientific concepts, including their "common misconceptions and roadblocks." Professional growth is facilitated by sustained immersion in colleagues' classes, combined with reflection on these classroom experiences. Superfine and Pitvorec's (2021) study offers insights into the development and articulation of a pedagogy of mathematics teacher education through the creation and analysis of lesson plans. Using a "problems of [mathematics teacher education] practice" focus, the novice teacher educator of this study develops her knowledge of practice supported by her more experienced colleagues. As the authors point out, the aim of the study is not to produce detailed lesson plans for every topic in mathematics teacher education, nor to create "blueprints" for practice, but to "potentially elucidate components of a knowledge base related to the content of lesson plans" through collaborative analysis of problems of practice. While this process is immediately helpful for this novice teacher educator, it may also help other teacher educators. Unique to this study is the elucidation and articulation of the pedagogical reasoning shaping the practice of the novice teacher educator.

We interpreted the studies by Hanuscin et al. (2021) and Superfine and Pitvorec (2021) as illustrating approaches that could be utilized by other teacher educators seeking to develop their PCK and Subject Matter Knowledge (SMK). This is an important contribution to the research on teacher educator professional growth as there are few examples of such detailed subject specific pedagogy of teacher education in the literature (with the possible exception of self-studies in mathematics (see Schuck \& Pereira, 2011) and science (see Bullock \& Russell, 2012)).

In addition to the studies described above, Venkat and Askew (2021) foreground subject matter knowledge through their study which aims to build the capacity and confidence of teacher educators (whom they refer to as Math Subject Advisors [MSAs]) to support primary school teachers in teaching a specific mathematical topic, multiplicative reasoning. An explicit purpose of this project was to build research informed mathematical knowledge and understanding of the MSAs. Outcomes of the research show that professional growth occurs for the MSAs in terms of the development of their SMK for multiplicative reasoning, and also in terms of their PCK of classroom teaching of this topic as they develop "more skilled pedagogic content knowledge" and "mathematically attuned noticing" through working with the teachers in the professional development program. They also develop their knowledge of teaching adult learners.

Teacher educators face unique challenges when working in interdisciplinary contexts because of the different subject cultures and epistemologies that teachers bring, as well as those encountered within the contexts in which they work. For example, Triantafillou et al.'s (2021) study takes a STEM focus as participating teacher educators' growth is investigated through their efforts to support collaboration among inservice mathematics and science teachers. In this study, teacher educators experienced difficulties and dilemmas as they attempted to navigate and manage their own, 
and inservice teachers' epistemological and ontological differences in mathematics and science teaching. Given increasing focus on interdisciplinary collaborations in mathematics and science teaching, this study (and also to some extent Hanuscin et al., 2021) raises important issues about the content-focused nature of teacher educators' professional knowledge. Both Hanuscin et al.'s (2021) and Triantafillou et al.'s (2021) studies offer approaches and insights that might be valuable to support teacher educators' professional growth in interdisciplinary learning.

In the remaining three studies, disciplinary knowledge sits more in the background because the focus of the study is on another aspect of growth — on identity (Lloyd et al., 2021; Weinberg et al., 2021) and a professional development model (Borko et al., 2021). In the study by Lloyd et al. (2021), teacher educators share the same disciplinary background of mathematics although they have different identity relationships with the content of mathematics, as a classroom teacher, researcher, and teacher educator. Their study findings illustrate a "differential attention to subject matter" that is shaped by the identity lens each teacher educator brings to bear on her observations of classroom teaching. The extent to which mathematics is foregrounded in their identities influences the nature of her observations and subsequent professional growth trajectory.

Weinberg et al.'s (2021) study also focuses on identity of teacher educators, but within an interdisciplinary STEM Community of Practice. This time, identity is connected with how the teacher educators identify with the different disciplines of STEM. Their study outcomes focus on identity transformations, mostly related to educational systems and contexts and within this, the role of disciplinary knowledge is evident through the teacher educators coming to understand their different epistemological orientations related to STEM. The study outcomes also illustrate the development of a pedagogy of teacher education for teaching STEM, although this is a more minor focus of the article. Given the increasing emphasis on interdisciplinary STEM, it would be useful in future studies to better understand what it means to develop as a teacher educator of STEM, where the focus is on understanding how to connect subject matter knowledge across the STEM disciplines.

Borko et al.'s (2021) study foregrounds teacher educators' learning and implementation of a particular professional development model in the context of mathematics instruction. The main focus of this article is on how the teacher educators (referred to as master teachers) developed their knowledge and capacity to use specific practices embedded in the model of lifting, nesting, and unpacking and how they modify the model as they work within different school contexts. From this study, we learn most about teacher educators' professional growth in terms of their use of the specific model and little about how the mathematics subject matter shapes the way in which the model is interpreted or enacted.

\section{Summary of Theme Two}

Looking across the set of articles, we notice that only a couple of papers pay attention to the idea that teacher educator professional growth includes a focus on subject matter knowledge of science, or mathematics. This is perhaps not surprising since the typical recruitment of teacher educators is from school teaching or academia; hence, having sufficient subject matter knowledge may be assumed as a prerequisite for the role. Yet, as Hanuscin et al.'s (2021) and Superfine and Pitvorec's (2021) studies show, there is 
something different about understanding the knowledge required for teaching teachers compared with teaching school students that needs to be identified and developed. At the same time, these studies also reveal that disciplinary knowledge plays an important role in shaping the professional identity of teacher educators, and that growing professionally also means recognizing how discipline and identity interact. Three studies investigate aspects of identity in relation to this theme both within a particular discipline (Lloyd et al., 2021) and across STEM disciplines (Triantafillou et al., 2021; Weinberg et al., 2021).

\section{Conclusion: Insights from this Special Issue}

As noted in the introduction to this special issue (Krainer et al., 2021), over the years much of what we have learned about mathematics and science teacher professional development has started to be taken up in understanding the professional growth of teacher educators. The support for introspective methodologies such as self-study and action research has paved the way for much of this work to be noticed and shared publicly (Bullock \& Russell, 2012; Loughran, 2014).

The seven articles in this special issue further contribute to this growing, but still very much needed development. From these studies, two themes have emerged on collaboration and the role of disciplinary knowledge. As we consider these two themes, we are reminded of what Loughran (2006) proposed as a distinct pedagogy of teacher education, and that it is based on two complementary aspects of knowledge and practice: teaching about teaching and learning about teaching. Drawing from Loughran's work, Ritter (2007) further highlighted a distinction between a pedagogy of classroom teaching and pedagogy of teacher education, whereby classroom teachers teach subject matter, while teacher educators teach about how to teach subject matter. Considering this perspective, and focusing on science teacher educators, Berry and Loughran (2012) noted the multifaceted challenges of the role of a teacher educator, and the need for science teacher educators specifically (and the same could be said for mathematics teacher educators, as elaborated in Even (2005) and Jaworski (2008)) that to experience and understand learning about science teaching and learning in ways that challenge their existing taken-for-granted assumptions about practice, they need to work on developing their pedagogy of (science/mathematics) teacher education. Looking across each of the studies in this special issue, one could say that these researchers have indeed taken up the idea to challenge their existing assumptions about practice, and they have done so in different ways, from different perspectives, and for different purposes.

In conclusion, we leave this special issue with a few important insights for science and mathematics teacher education researchers to consider as they attempt to challenge their own assumptions about their practice, or the developing practice of teacher educators with whom they work. First, it is important to explicate and share what and how teacher educators' knowledge continues to grow throughout a career in academia, as it is just as important for academics of teacher education to push the boundaries of understanding who they are and their approaches to teaching teachers for the field of teacher education to continue to evolve. Next, within the field of mathematics and science teacher education specifically, it is important that we try to identify 
the role that subject matter or disciplinary knowledge continues to play in establishing a specialized knowledge (i.e. PCK; Shulman, 1986) of teaching teachers (Abell et al., 2009). Through purposeful study of these relationships between knowledge and practice (Loughran, 2006), only then can we begin to identify possible key processes or experiences needed for professional growth, in turn promoting both theory and practice of teacher education. Thirdly, these seven studies show various approaches to studying a range of teacher educator professional growth experiences; however, it is also evident there is not a single kind of teacher educator, but it is a broad term used to describe someone who works to educate teachers in a variety of contexts. As such, it is important that the field begin to find some common or shared language to describe the processes of professional growth for a range of teacher educators that help to define the expertise and development of educators of teachers in the disciplines of science and mathematics. Only through this use of shared language can the kinds of experiences and trajectories of growth, as Abell et al. (2009) proposed, begin to be studied, interrogated, and refined to grow and develop the profession. Lastly, from the variance displayed in these seven studies as to who is referred to as a teacher educator, to the goals for seeking out professional growth, to understanding both shared approaches (i.e. collaboration) and contrasting approaches (e.g. evaluation of professional development models to self-studies), it is clear there is a need for further study on the professional development of science and mathematics teacher educators - both in distance (larger scale) and nearness (more fine-grained). Both kinds of research will help to illustrate, and hopefully disentangle, the complex, multi-layered, and multifactorial task of understanding how to study teacher educators' learning and development, a goal that these studies point the way towards and help to shed light on as necessary for future studies.

Funding Open access funding provided by University of Klagenfurt.

Open Access This article is licensed under a Creative Commons Attribution 4.0 International License, which permits use, sharing, adaptation, distribution and reproduction in any medium or format, as long as you give appropriate credit to the original author(s) and the source, provide a link to the Creative Commons licence, and indicate if changes were made. The images or other third party material in this article are included in the article's Creative Commons licence, unless indicated otherwise in a credit line to the material. If material is not included in the article's Creative Commons licence and your intended use is not permitted by statutory regulation or exceeds the permitted use, you will need to obtain permission directly from the copyright holder. To view a copy of this licence, visit http://creativecommons.org/licenses/by/4.0/.

\section{References}

Abell, S. K., Park Rogers, M. A., Hanuscin, D., Lee, M. H., \& Gagnon, M. J. (2009). Preparing the next generation of science teacher educators: A model for developing PCK for teaching science teachers. Journal of Science Teacher Education, 20, 77-93. https://doi.org/10.1007/s10972-008-9115-6.

Anderson, C. W. (2007). Perspectives on science learning. In S. K. Abell, \& N. G. Lederman (Eds.). Handbook of research in science education (Vol. 1, pp. 3-30). Routledge Publishers, Taylor and Francis Group. 
Berry, A., \& Loughran, J. J. (2012). Developing science teacher educators' pedagogy of teacher education. In B. Fraser, K. Tobin, \& C. McRobbie (Eds.), Second international handbook of science education (pp. 401-415). Springer.

Borko, H. \& Potari, D. (Eds.). (2020). Proceedings of the twenty-fifth ICMI study: Teachers of mathematics working and learning in collaborative groups. International Commission on Mathematical Instruction. http://icmistudy25.ie.ulisboa.pt/wp-content/uploads/2020/05/ICMIStudy25Proceedings.pdf.

Borko, H., Carlson, J., Deutscher, R., Boles, K. L., Delaney, V. L., Fong, A. B., Jarry-Shore, A., Malamut, J., Million, S., Mozenter, S., \& Villa III, A. M. (2021). Learning to lead: An approach to mathematics teacher leader development. International Journal of Science and Mathematics Education, 19(Suppl. 1). https://doi.org/10.1007/s10763-021-10157-2.

Bullock, S. M., \& Russell, T. (Eds.). (2012). Self-studies of science teacher education practices. Springer.

Cuenca, A., \& Park Rogers, M. (2019). Confronting the ethics of power in collaborative self-study research. In R. Brandenburg \& S. McDonough (Eds.), Ethics, self-study research methodology and teacher education (pp. 45-59). Springer Nature. https://doi.org/10.1007/978-981-32-9135-5_4.

Even, R. (2005). Integrating knowledge and practice at MANOR in the development of providers of professional development for teachers. Journal of Mathematics Teacher Education, 8, 343-357. https:// doi.org/10.1007/s10857-005-0855-3.

Hanuscin, D., Donovan, D., Acevedo-Gutierrez, A., Borda, E., DeBari, S., Melton, J., Le, T., Morrison, W., \& Ronca, R. (2021). Supporting the professional development of teacher educators through shadowing. International Journal of Science and Mathematics Education, 19(Suppl. 1). https://doi.org/10.1007/ s10763-021-10154-5.

Heyd-Metzuyanim, E. (2017). A meta-level reflection on dialogue between discourses. In J. Adler \& A. Sfard (Eds.), Research for educational change: Transforming researchers' insights into improvement in mathematics teaching and learning (pp. 198-209). Routledge.

Jaworski, B. (2008). Development of the mathematics teacher educator and its relation to teaching development. In B. Jaworski \& T. Wood (Eds.), International handbook of mathematics teacher education (Vol. 4, pp. 177-199). Sense Publishers.

Krainer, K., Even, R., Park Rogers, M., \& Berry, A. (2021). Research on learners and teachers of mathematics and science: Forerunners to a focus on teacher educator professional growth. International Journal of Science and Mathematics Education, 19(Suppl. 1).

Laal, M., \& Ghodsi, S. M. (2012). Benefits of collaborative learning. Procedia - Social and Behavioral Sciences, 31, 486-490. https://doi.org/10.1016/j.sbspro.2011.12.09.

Lave, J., \& Wenger, E. (1991). Situated learning: Legitimate peripheral participation. Cambridge University Press. https://doi.org/10.1017/CBO9780511815355.

Lloyd, G. M., de Carle, A., \& Coon-Kitt, M. J. (2021). When you're with me, I'm learning: A duoethnography of teacher educators' identities in relation to observing preservice teachers' emergent mathematics instruction. International Journal of Science and Mathematics Education, 19(Suppl. 1). https://doi.org/ 10.1007/s10763-021-10162-5.

Loughran, J. J. (2006). Developing a pedagogy of teacher education: Understanding teaching and learning about teaching. Routledge.

Loughran, J. (2014). Professionally developing as a teacher educator. Journal of Teacher Education, 65(4), 271-283. https://doi.org/10.1177/0022487114533386.

McDonald, M., Kazemi, E. \& Kavanagh, S. S. (2013). Core practices and pedagogies of teacher education: A call for a common language and collective activity. Journal of Teacher Education, 64(5), 378-386.

Mena, J., \& Russell, T. (2017). Collaboration, multiple methods, trustworthiness: Issues arising from the 2014 international conference on self-study of teacher education practices. Studying Teacher Education, 13, 105-122. https://doi.org/10.1080/17425964.2017.1287694.

Morrison, J. A., Raab, F., \& Ingram, D. (2009). Factors influencing elementary and secondary teachers' views on the nature of science. Journal of Research in Science Teaching, 46(4), 384-403.

National Research Council. (2005). How students learn: History, mathematics, and science in the classroom (p. 10.17226/10126). The National Academies Press.

Newman, S., \& Latifi, A. (2021). Vygotsky, education, and teacher education. Journal of Education for Teaching, 47, 4-17. https://doi.org/10.1080/02607476.2020.1831375.

Ping, C., Schellings, G., \& Beijaard, D. (2018). Teacher educators' professional learning: A literature review. Teaching and Teacher Education, 75, 93-104. https://doi.org/10.1016/j.tate.2018.06.003.

Prediger, S., \& Pöhler, B. (2019). Conducting PD discussions on language repertoires: a case study on facilitators' practices. In M. Graven, H. Venkat, A. Essien, \& P. Vale (Eds.), Proceedings of 43rd Annual Meeting of the International Group for the Psychology of Mathematics Education (PME 43) (Vol. 3, pp. 241-248). PME. 
Ritter, J. K. (2007). Forging a pedagogy of teacher education: The challenges of moving from classroom teacher to teacher educator. Studying Teacher Education, 3, 5-22. https://doi.org/10.1080/ 17425960701279776.

Schuck, S., \& Pereira, P. (2011). What counts in mathematics education? In S. Schuck \& P. Pereira (Eds.), What counts in teaching mathematics: Adding value to self and content (pp. 1-12). Springer.

Shulman, L. S. (1986). Those who understand: Knowledge growth in teaching. Educational Researcher, 15(2), 4-14. https://doi.org/10.3102/0013189X015002004.

Superfine, A. C., \& Pitvorec, K. (2021). Using community artifacts to support novice math teacher educators in teaching prospective teachers. International Journal of Science and Mathematics Education, 19(Suppl. 1). https://doi.org/10.1007/s10763-021-10152-7.

Triantafillou, C., Psycharis, G., Potari, D., Bakogianni, D., \& Spiliotopoulou, V. (2021). Teacher educators' activity aiming to support inquiry through mathematics and science teacher collaboration. International Journal of Science and Mathematics Education, 19(Suppl. 1). https://doi.org/10.1007/s10763-021-101536.

van der Linden, J., Erkens, G., Schmidt, H., \& Renshaw, P. (2000). Collaborative learning. In R. J. Simons, J. van der Linden, \& T. Duffy (Eds.), New learning (pp. 37-54). Springer. https://doi.org/10.1007/0-30647614-2_3.

Venkat, H., \& Askew, M. (2021). Development in South African primary mathematics teacher educators' work with in-service teachers. International Journal of Science and Mathematics Education, 19(Suppl. 1). https://doi.org/10.1007/s10763-021-10161-6.

Weinberg, A. E., Balgopal, M. M., \& Sample McMeeking, L. B. (2021). Professional growth and identity development of STEM teacher educators in a community of practice. International Journal of Science and Mathematics Education, 19(Suppl. 1). https://doi.org/10.1007/s10763-020-10148-9.

Wenger, E. (1998). Communities of practice: Learning, meaning, and identity. Cambridge University Press. https://doi.org/10.1017/CBO9780511803932. 